\title{
Efficacy and mortality of rotating sheaths versus laser sheaths for transvenous lead extraction: a meta-analysis
}

\author{
Sun Yong Lee ${ }^{1,2}$ - Isabel E. Allen ${ }^{3} \cdot$ Celso Diaz ${ }^{4,5} \cdot$ Xiaofan Guo $^{3,6} \cdot$ Cara Pellegrini $^{1,7} \cdot$ Ramin Beygui $^{8}$. \\ Ricardo Cardona-Guarache ${ }^{9} \cdot$ Gregory M. Marcus $^{1} \cdot$ Byron K. Lee $^{1}$
}

Received: 6 April 2021 / Accepted: 22 September 2021

(c) The Author(s) 2021

\begin{abstract}
Background Rotating and laser sheaths are both routinely used in transvenous lead extraction (TLE) which can lead to catastrophic complications including death. The efficacy and risk of each approach are uncertain. To perform a meta-analysis to compare success and mortality rates associated with rotating and laser sheaths.

Methods We searched electronic academic databases for case series of consecutive patients and randomized controlled trials published 1998-2017 describing the use of rotating and laser sheaths for TLE. Among 48 studies identified, rotating sheaths included 1,094 patients with 1,955 leads in 14 studies, and laser sheaths included 7,775 patients with 12,339 leads in 34 studies. Patients receiving rotating sheaths were older (63 versus 60 years old) and were more often male (74\% versus $72 \%$ ); CRT-P/Ds were more commonly extracted using rotating sheaths (12\% versus $7 \%$ ), whereas ICDs were less common (37\% versus $42 \%$ ), $p>0.05$ for all. Infection as an indication for lead extraction was higher in the rotating sheath group $(59.8 \%$ versus $52.9 \%, p=0.002)$. The mean time from initial lead implantation was 7.2 years for rotating sheaths and 6.3 years for laser sheaths $(p>0.05)$.

Results Success rates for complete removal of transvenous leads were $95.1 \%$ in rotating sheaths and $93.4 \%$ in laser sheaths $(p<0.05)$. There was one death among 1,094 patients $(0.09 \%)$ in rotating sheaths and 66 deaths among 7,775 patients $(0.85 \%)$ in laser sheaths, translating to a 9.3-fold higher risk of death with laser sheaths (95\% CI 1.3 to $66.9, p=0.01$ ).

Conclusions Laser sheaths were associated with lower complete lead removal rate and a 9.3 -fold higher risk of death.
\end{abstract}

Keywords Transvenous lead extraction $\cdot$ Laser sheaths $\cdot$ Rotating sheaths $\cdot$ CIEDs $\cdot$ Mortality

$\begin{array}{ll}\text { Abbreviations } \\ \text { TLE } & \text { Transvenous lead extraction } \\ \text { CIEDs } & \text { Cardiac implantable electronic devices } \\ \text { RCTs } & \text { Randomized controlled trials } \\ \text { EHRA } & \text { European Heart Rhythm Association } \\ \text { NICE } & \text { National Institute for Clinical Excellence } \\ \text { PM } & \text { Pacemaker } \\ \text { ICD } & \text { Implantable cardioverter defibrillator } \\ \text { CRTP/D } & \text { Cardiac resynchronization therapy pacemaker/ } \\ & \text { defibrillator } \\ \text { ES } & \text { Effect size } \\ \text { CI } & \text { Confidence interval }\end{array}$

Systematic review registration to PROSPERO: registration number CRD42017081076

Sun Yong Lee

sunyong.lee55@gmail.com

Extended author information available on the last page of the article
SVC Superior vena cava

RA Right atrium

RV Right ventricle

$\mathrm{CA} / \mathrm{T} \quad$ Cardiac avulsion or tear

$\mathrm{VA} / \mathrm{T} \quad$ Vascular avulsion or tear

$\mathrm{P} / \mathrm{C} / \mathrm{S} \quad$ Pericardiocentesis/chest tube/surgical procedure

\section{Introduction}

The rate of cardiac implantable electronic device (CIED) implantation and life expectancy has increased worldwide over recent years $[1,2]$. As a result, the need for transvenous lead extraction (TLE) has also increased. TLE is a challenging procedure as there are risks of fibrous adhesions between the leads, vascular wall, and endocardial surface. These structures can tear during TLE which can lead serious complications such as cardiovascular injury and death. In 
order to prevent these complications, advanced procedures are commonly used $[1,2]$. The two common approaches to TLE utilize either laser sheaths or rotating sheaths [3]. To disrupt the fibrotic attachments of indwelling leads, laser sheaths employ fiber-optics to transmit desiccating laser light while rotating sheaths utilize a revolving bladed distal tip [1, 3, 4]. Although, technology improvements have increased efficacy and safety, TLE procedures can still lead to serious, life-threatening complications including death [1, $3,5]$. Laser sheaths are more commonly utilized world-wide, setting the stage for a familiarity or even allegiance bias among operators. However, there are now several case series describing the outcome of patients who undergo TLE with either the laser sheath or the rotating sheath published in the peer-reviewed literature, but no large studies comparing these two approaches directly [6]. We therefore performed a meta-analysis to summarize these data in hopes of providing clinically relevant estimates based on the peer-reviewed literature regarding the relative efficacy and safety of these two approaches.

\section{Methods}

We systematically searched PubMed, Embase in September 2017 using the following medical subject heading terms: transvenous lead extraction, mechanical dilator sheath, Evolution mechanical dilator sheath, laser sheaths, Excimer laser, pacemaker, defibrillator. Two authors (L. SY, L. BK) independently extracted the data after predefined search criteria.

Studies were included in this meta-analysis if they met all the following eligibility criteria:

1. Case series of consecutive patients or randomized controlled trials (RCTs)

2. Reporting more than ten patients and including a minimum set of data: number of subjects undergoing TLE and number of extracted leads, mean age of the patients, lead age, type of device, success rate, and number of deaths

\section{Written in English}

Studies were excluded if they were:

\section{Systematic reviews}

2. Letters

3. Point-of-views or editorials

If the same center(s) produced different publications with duplicate cases reported due to time window overlapping, only the study with the highest number of patients (usually the one published latest) was included. If more than one group of patients was described in the same study, the groups were handled as if they were from two separate studies.

Complete procedural success was defined as the removal of all targeted leads and all lead material from the vascular space, with the absence of any permanently disabling complication or procedure related death $[1$, $6,7]$. Clinical success was defined as the removal of all targeted leads and lead material from the vascular space, or retention of a small portion of the lead that does not negatively impact the outcome goals of the procedure. Failure was defined as inability to achieve either complete procedural or clinical success, or the development of any permanently disabling complication or procedure-related death. Any permanently disabling complication included cardiac avulsion or tear requiring surgical interventions, vascular avulsion or tear requiring surgical interventions, pulmonary embolism requiring surgical interventions, or stroke.

The main goal of the analysis was to compare the efficacy and safety of laser sheaths and rotating sheaths. Several stratified meta-analyses were performed to find the risk of bias including center volume, length of lead age, device type, and publication year [2]. For center volume, Lexicon $[2,8]$ criteria were used based on the number of procedures performed over 4 years per site as indicated in Online Supplemental Table S1. In order to provide a more objective analysis, we focused on procedure-related death and complete procedure success rate. Major or minor complications were not considered since the definitions of these complications were variable among studies. We also analyzed TLE indication in the two procedure groups and we restricted to studies published 2009 or later in both procedures to reduce temporal bias.

We included in the meta-analysis only the studies on laser sheaths and rotating sheaths for TLE procedures. Since almost all included studies were observational case series except two RCTs, no traditional meta-analysis of head-to-head comparisons was possible $[2,9]$. We therefore used meta-analyses of proportions to combine data from each case series to get summary estimates of the absolute risk of each safety outcome and the Meta-analysis Of Observational Studies in Epidemiology (MOOSE) statement was applied [10]. Summary estimates were produced using random effects meta-analyses to control for heterogeneity between studies. Sensitivity analyses were examined using meta-regression and subgroup analyses. Baseline characteristics of the studies used means (standard deviations) for continuous variables and counts (percents) for categorical data. Comparison between groups used Student's $t$-test for continuous variables and chisquared tests for categorical variables. All analyses used Stata 15.1 (College Station, TX). 


\section{Results}

The literature search for randomized trials yielded 55 studies in PubMed and an additional 3 in Embase. Two of these randomized trials included laser sheaths. In the next-step, a broader search was conducted after deleting "randomized" and adding procedure-specific terms (Fig. 1). The literature search on rotating sheaths yielded 628 studies by PubMed and 337 studies by Embase. On review of the titles and abstracts, 929 studies were excluded as being unrelated to the field of research or clearly identifying a type of manuscript in the systematic review: reviews, letters, editorials, and case reports of $\leq 10$ subjects. Total 14 studies on rotating sheaths were included for meta-analysis which met eligibility criteria.

Eight hundred seventy-two studies were found in PubMed and 437 studies in Embase on laser sheaths. A total of 1269 studies were excluded as being unrelated to the field of research or clearly identifying a type of manuscript included in the systematic review: reviews, letters, editorials, and case reports of $\leq 10$ subjects. Seven out of 41 studies on laser sheaths were further excluded for not satisfying eligibility criteria. A total of 34 studies on laser sheaths were included for meta-analysis.

In total, 48 rotating and laser sheath studies met eligibility criteria and were included in the meta-analysis: 2 were RCTs [11, 12]; 3 were prospective observational studies [7, $13,14]$; and 43 had a retrospective observational design [6, $8,11,15-53]$.

The 48 identified studies described 8,869 patients who underwent attempted extraction of 14,294 leads with rotating sheaths or laser sheaths (Table 1, Online Supplemental
Table S2-3) [5-8, 11-54]. The patients undergoing TLE with rotating sheaths were older and were more often male. Within the rotating sheath group, CRT-P/Ds were more commonly extracted, whereas ICDs were less common than the laser sheath group ( $p>0.05$ for all). Complete procedural success per lead was achieved in approximately $95 \%$ of cases utilizing a rotating sheath (pooled estimate of 11/ 14 studies) and $93 \%$ of cases utilizing a laser sheath (pooled estimate of 21/34 studies) [22].

The total number of procedure-related deaths in both groups was 67: one out of 1,094 patients $(0.09 \%)$ in the rotating sheath group and 66 out of 7,775 patients $(0.85 \%)$ in the laser sheath group, translating to a 9.3-fold higher risk of death with laser sheaths (95\% CI 1.3 to $66.9, p=0.01$ ). The causes of deaths for patients who underwent rotating or laser sheath lead extraction are shown in Table 2. The one patient death associated with a rotating sheath resulted from cardiovascular injury [17]. The portion of deaths due to cardiovascular injury following laser sheath procedures was $39.4 \%(26 / 66)$. The superior vena cava (SVC) was the most common site of injury accounting for over $30 \%$ of cases (Table 3).

We analyzed TLE indication in the two groups (Table 4). Infection was more often an indication for extraction in the rotating sheath group at $59.8 \%$ compared to the laser group at $52.9 \%, p=0.0002$.

When we limited analyses to medium- and high-volume centers by using hospital-volume Lexicon study criteria, complete procedural lead removal was achieved in $95 \%$ of cases in the rotating sheath group and $93 \%$ of cases in the laser sheath group $(p<0.05)[2,8,55]$. Among mediumand high-volume centers, the mortality rate was $0 \%(0 / 841)$
Fig. 1 Flow of the included studies in each stage of the bibliographic search as per PRISMA checklist

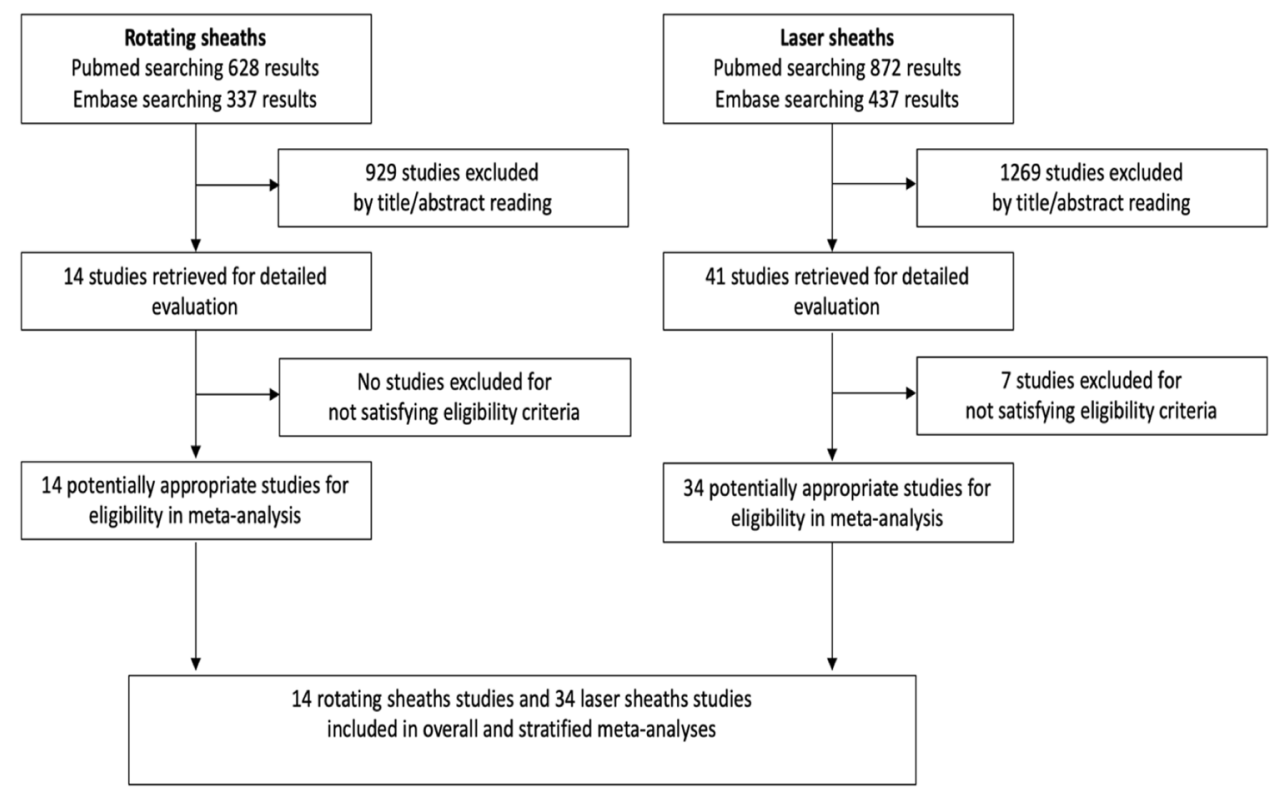


Table 1 Baseline characteristics of two procedures

\begin{tabular}{|c|c|c|c|c|c|}
\hline & & Rotating sheaths & Laser sheaths & $P$ & $R R$ \\
\hline \multicolumn{2}{|l|}{ Age (years, mean $\pm S D$ ) } & $62.68 \pm 3.906$ & $59.78 \pm 12.72$ & 0.44 & - \\
\hline \multicolumn{2}{|l|}{ Male $(\% \pm \mathrm{SD})$} & $73.70 \pm 8.442$ & $71.74 \pm 9.651$ & 0.54 & - \\
\hline \multicolumn{2}{|l|}{ Patient number } & 1,094 & 7,775 & - & - \\
\hline \multicolumn{2}{|l|}{ Number of leads } & 1,955 & 12,339 & - & - \\
\hline \multicolumn{2}{|l|}{ Lead age (years, mean $\pm S D$ ) } & $7.164 \pm 1.441$ & $6.278 \pm 2.173$ & 0.17 & - \\
\hline \multirow[t]{3}{*}{ Implanted device } & $\%$ of $\mathrm{PM}(\% \pm \mathrm{SD})$ & $52.88 \pm 18.17$ & $46.86 \pm 31.88$ & 0.58 & - \\
\hline & $\%$ of ICD $(\% \pm \mathrm{SD})$ & $36.76 \pm 15.69$ & $41.73 \pm 30.77$ & 0.59 & - \\
\hline & $\%$ of CRT-P/D $(\% \pm \mathrm{SD})$ & $12.17 \pm 16.53$ & $7.267 \pm 12.77$ & 0.35 & - \\
\hline \multirow[t]{2}{*}{ Indications for TLE } & Infective & $495(59.8 \%)$ & $3,291(52.9 \%)$ & 0.0002 & - \\
\hline & Non-infective & $333(40.2 \%)$ & $2,932(47.1 \%)$ & - & - \\
\hline \multicolumn{2}{|c|}{ Complete procedural success rate per leads (\%) } & 95.1317 & 93.3936 & 0.0069 & $\mathrm{RR}=1.357$ \\
\hline \multicolumn{2}{|l|}{ Clinical success rate $(\% \pm \mathrm{SD})$} & $99.18 \pm 1.043$ & $96.72 \pm 6.245$ & 0.19 & - \\
\hline \multicolumn{2}{|l|}{ Death rate (\%) } & $1 / 1094(0.09)$ & $66 / 7775(0.85)$ & 0.011 & $\mathrm{RR}=9.287$ \\
\hline
\end{tabular}

$P, p$ value; $R R$, relative risk; $S D$, standard deviation; $C I$, confidence interval; $P M$, pacemaker; $I C D$ implantable cardioverter defibrillator; $C R T$ $P / D$, cardiac resynchronization therapy pacemaker/defibrillator

in the rotating sheath group and $0.87 \%(62 / 7094)$ in laser sheath group $(p=0.01)$.

When we restricted analyses to years 2009-2017 to control for temporal bias since rotating sheaths were introduced in 2009, complete procedural lead removal rate was $95.1 \%$ in the rotating sheath group and $96.7 \%$ in the laser sheath group $(p<0.05)$. The total death number was 1 out of 1,094 patients in the rotating group $(0.09 \%)$ and 41 out of 4,313 patients $(0.95 \%)$ in the laser group, translating to a 10.4 -fold higher risk of death with laser sheaths (95\% CI 1.4 to 75.6, $p=0.004)$.

The results of separate analyses for RCTs and observational case series studies are presented in Online Supplemental Tables S4-S8. In one of the two RCTs, information

Table 2 Cause of death for patients who underwent rotating or laser sheath lead extraction

\begin{tabular}{lll}
\hline & $\begin{array}{l}\text { Rotating sheath } \\
\text { extraction } \\
N(\%)\end{array}$ & $\begin{array}{l}\text { Laser } \\
\text { sheath } \\
\text { extraction } \\
N(\%)\end{array}$ \\
& & $26(39.4)$ \\
\hline $\begin{array}{l}\text { Confirmed/suspected Cardiovascular } \\
\quad \text { Injury }\end{array}$ & $1(100)$ & \\
Pulmonary embolism & - & $2(3.0)$ \\
Arrhythmia & - & $2(3.0)$ \\
Infection & - & $27(40.9)$ \\
$\quad$ Sepsis & - & $3(4.5)$ \\
$\quad$ Endocarditis & - & $1(1.5)$ \\
$\quad$ Endocarditis or pocket infection & - & $23(34.8)$ \\
Renal failure & - & $2(3.0)$ \\
Unknown & - & $7(10.6)$ \\
\hline
\end{tabular}

was limited in allocation concealment, selective outcome reporting, and blinding of participants and personnel [11]. All included studies showed low or unclear risk of bias for all other domains. Forty-six case series studies presented a score of four to eight of the eight points according to the scale adopted by NICE.

As shown in Table 1 and Online Supplemental Tables S2-3, studies were heterogeneous in that they had various numbers of enrolled populations and different hospital volumes, and there are fewer studies (publication study from 2009) for rotating sheaths being a newer device. The metaanalysis of 48 studies showed a high heterogeneity between the studies for the complete procedural success rate (test for heterogeneity 250.60 , degree of freedom $=28, p<0.009$,

Table 3 Cardiovascular structures injured during the procedure amongst patients that died during rotating or laser sheath lead extraction

\begin{tabular}{lll}
\hline & $\begin{array}{l}\text { Rotating } \\
\text { sheath extrac- } \\
\text { tion } \\
N(\%)\end{array}$ & $\begin{array}{l}\text { Laser } \\
\text { sheath } \\
\text { extraction } \\
N(\%)\end{array}$ \\
\hline Unknown & $1(100)$ & $12(46.2)$ \\
Superior vena cava & - & $7(26.9)$ \\
Right ventricle & - & $2(7.7)$ \\
Right atrium & - & $1(3.8)$ \\
Anomalous innominate arteriovenous & - & $1(3.8)$ \\
$\quad$ fistula & & $1(3.8)$ \\
Subclavian vein & - & $1(3.8)$ \\
Superior vena cava to right atrium & - & $1(3.8)$ \\
Inferior vena cava to right atrium & - &
\end{tabular}


Table 4 Analysis of TLE indications

\begin{tabular}{lll}
\hline & $\begin{array}{l}\text { Rotating sheath } \\
\text { patient number }(\%)\end{array}$ & $\begin{array}{l}\text { Laser sheath } \\
\text { patient number } \\
(\%)\end{array}$ \\
\hline $\begin{array}{c}\text { Endocarditis, pocket infec- } \\
\text { tion, or systemic infection }\end{array}$ & $495(59.8 \%)$ & $3,291(52.9 \%)$ \\
Lead malfunction & $215(26.0 \%)$ & $1,647(26.5 \%)$ \\
Lead displacement & $2(0.2 \%)$ & $445(7.2 \%)$ \\
Upgrade the device & $91(11.0 \%)$ & $109(1.8 \%)$ \\
Chronic pain & $2(0.2 \%)$ & $47(0.8 \%)$ \\
Venous thrombosis & $1(0.1 \%)$ & $84(1.3 \%)$ \\
Other & $22(2.7 \%)$ & $600(9.6 \%)$ \\
Total & 828 & 6,223 \\
\hline
\end{tabular}

Indications were analyzed when data available

$\left.I^{\wedge}=88.83 \%\right)$. The heterogeneity for the death rate (test for heterogeneity 54.26, degree of freedom $=45, p=0.16$, $I^{\wedge^{2}}=17.06 \%$ ) was not highly variable.

In a meta-regression analysis, our study showed that the lead age and percent of ICD leads did not prove to be significantly associated with any of the outcomes among the various subgroups. The detailed analysis is available in supplemental materials with Online Supplemental Figures S1-S6.

\section{Discussion}

The primary finding of this meta-analysis of 48 studies involving 8,869 patients is that laser sheaths are associated with a lower complete lead removal rate $(93 \%$ vs. $95 \%$ for rotating sheath, $p<0.05)$ and a 9.3-fold higher risk of death $(95 \%$ CI 1.3 to $66.9, p=0.01$ ). The difference in mortality remained unchanged when the analysis is limited to studies from mediumand high-volume centers or studies performed 2009 or later. These mortality results are consistent with a recently published study based on mortality data obtained from the Manufacturer and User Facility Device Experience (MAUDE) database which found lead removal using laser sheaths to be associated with approximately 7 times greater risk of death when compared to rotating sheaths (95\% CI 4.1 to $12.7, p<0.0001$ ) [56].

Although low-volume centers have been found to have a higher rate of death and complications compared to highvolume centers, this did not account for our findings [2]. The comparison of complete lead removal rate remained similar when limiting analysis to studies from medium- and highvolume centers (95\% vs. $93 \%$ for laser sheath, $p<0.05$ ) and mortality was still higher with laser sheaths $(0 \%$ vs. $0.87 \%$ for laser sheath).

Since the rotating sheaths were introduced over 10 years after the laser sheath, we were concerned that temporal bias could be playing a role in our findings. However, limiting analysis of complete lead removal to studies starting in 2009 (when the first rotating sheath study was published) found similar complete removal rates $(96.7 \%$ vs. $95.1 \%$ for rotating sheath) and still a 10.4-fold higher risk of death (95\% CI 1.4 to 75.6, $p=0.004$ ) in laser sheath.

As we expected, one of the main causes of death from TLE is cardiovascular injuries. SVC is the most commonly injured structure (Table 3). The mechanism of SVC injury is unclear. Although the penetration of the laser sheath has been reported to be shallow, repeated activation of the laser sheath at a site of heavy fibrosis may lead to buildup of thermal injury and, as a result, cause vascular injuries. SVC injury may be less likely with rotating sheaths because the cutting tip is only $1.27 \mathrm{~mm}$ thick (Cook Evolution). Therefore, only tissue very near the sheath tip (and lead body) can be affected [12].

The ancillary analysis of the ELECTRa (European Lead Extraction ConTRolled) study supports our findings [57]. They looked at the major cardiac and vascular complications after TLE and also found that rotating sheaths had lower incidence of complication compared to laser sheaths. The number of CV major complications, 49 among 3,510 patients who underwent TLE, such as vascular avulsion or tear $(\mathrm{VA} / \mathrm{T})$ due to SVC laceration and cardiac avulsion or tear $(\mathrm{CA} / \mathrm{T})$ with tamponade was higher with laser sheaths $19.06 \%$ compared to rotating sheaths $7.61 \%(p<0.002)$. Both $\mathrm{CA} / \mathrm{T}$ and VA/T requiring pericardiocentesis/chest tube/surgical procedure $(\mathrm{p} / \mathrm{c} / \mathrm{s})$ were higher in laser sheaths than in rotating sheaths. However, mortality rate with each sheath type is not reported.

It is unclear why laser sheaths were associated with more non-cardiovascular deaths, which included deaths due to pulmonary embolism, arrhythmia, infection, renal failure, and unknown causes. We speculate that some of these deaths were due to unrecognized cardiovascular injury, perhaps in cases where there was no autopsy. Additionally, the heat generated by the laser may promote clotting, embolization, electrical ectopy, or vegetation dissolution that may also lead to some of these non-cardiovascular deaths.

A new intravenous occlusion balloon designed to seal accidental tears in the SVC during TLE was introduced in July 2016 by Spectranetics Corporation (Colorado Springs, $\mathrm{CO})$ [58]. However, this device was recalled due to the possibility of a blocked guidewire lumen in some units which would delay life-saving treatment and may result in immediate and serious adverse consequences including death. Our study was unable to assess the impact of the intravenous occlusion balloon since many of the studies analyzed were from before July 2016 and few of the later studies disclosed its availability. Although widespread of availability of this device may decrease mortality rates associated with both rotating and laser sheaths, it would not prevent the initial occurrence of an SVC tear which is a serious complication to be avoided. 
Another factor that may influence success rate and mortality is the indication for lead removal. The LexICon study showed that patients with infection (as an indication for lead removal) tend to have worse short-term prognosis [8]. Therefore, we analyzed indications for procedure to see if there were any imbalance among patient groups as there was a concern that patients who underwent laser sheath TLE might be sicker and less stable. In both groups, there were no significant differences in TLE indications (Table 4). Interestingly, the rotating sheath group had a slightly higher proportion of infection ( $59.8 \%$ vs $52.9 \%$ for laser sheath) despite of a lower death rate. Therefore, infection cannot explain the higher risk of mortality seen with laser sheaths.

Our results are similar to those reported in a smaller metaanalysis that reviewed different TLE approaches including simple traction, classic mechanical, laser sheaths, and rotating sheaths. This study demonstrated that the risk of death or major complication was higher with the use of laser sheaths when compared to mechanical methods [4].

Our meta-regression studies showed that the study year, lead age, and hospital volume do not affect the death rate comparison. There was a higher death rate among pacemaker patients in both laser and rotating sheath groups. This finding contrasts a previous observation that dual coiled ICD lead is an independent risk factor predicting major complications [4]. Our meta-regression analysis also showed that the complete procedure success rate improved over time with the progression of study years in both laser and rotating sheath procedures. This finding is in line with the results of a study by Ghosh et al., which can be attributed to a learning effect [52]. When patients were divided into three consecutive groups by study years, complete success rate was higher in the latter third. However, as noted above, limiting analysis to studies starting in 2009 (when the first rotating sheath study was published) or later found similar complete removal rates with the two sheath types, and still a much higher risk of death with laser sheaths.

Recognizing that conclusions from meta-analyses are not definitive, we consider our result hypothesis generating and warranting further research. A randomized controlled trial comparing laser sheaths to rotating sheaths would be valuable.

\section{Study limitations}

There are several limitations of our meta-analysis and meta-regression analysis. First, our study was not based on randomized-controlled trials like traditional meta-analyses. Instead, our analyses relied mainly on case series studies which can potentially introduce selection bias. There was also high heterogeneity among the total sets of selected studies. We made several efforts to minimize these possible biases. We confirmed that both procedures were performed in groups with similar indications. Subgroup analysis sorted by hospital volume and study year yielded conclusions similar to our main findings.

Second, there were technological advances in both groups which could have affected the results. During the study time frame, for laser sheaths, there was the introduction of the $80-\mathrm{Hz}$ laser which replaced the $40-\mathrm{Hz}$ laser. For rotating sheaths, there was the introduction of the Cook Medical bidirectional rotating sheath which replaced their unidirectional rotating sheath, and Spectranetics introduced the TightRail rotating sheath in 2014. In general, studies did not indicate the sub-types of laser sheath or rotating cutting sheath used and therefore, its effect on the results could not be determined.

Finally, crossovers to the other sheath type during TLE could have also affected the results. However, we reviewed the studies and there was no mention of crossover noted in rotating sheath studies. In contrast, a few of the laser studies noted crossover. In Fu et al., one of the studies in the laser sheath group, they used a rotating sheath when laser extraction was not successful. However, they analyze the groups separately and the major complication rate was $0 \%$ with crossover to rotating sheaths and $3.7 \%$ in laser only extraction procedures [27]. In Starck et al., they allowed the crossover from mechanical to laser or vice versa, yet crossover never occurred [33]. Therefore, the chance of bias due to crossover is low.

\section{Conclusion}

Despite greater comorbidities in those undergoing extraction using rotating sheaths, our meta-analysis found that laser sheaths were associated with lower complete lead removal rate and a 9.3-fold higher risk of death.

Supplementary Information The online version contains supplementary material available at https://doi.org/10.1007/s10840-021-01076-x.

\section{Declarations}

Author disclosures All authors have reported that they have no relationships relevant to the contents of this paper to disclose.

Ethical approval Not applicable.

Conflict of interest The authors declare no competing interests.

Open Access This article is licensed under a Creative Commons Attribution 4.0 International License, which permits use, sharing, adaptation, distribution and reproduction in any medium or format, as long as you give appropriate credit to the original author(s) and the source, provide a link to the Creative Commons licence, and indicate if changes were made. The images or other third party material in this article are 
included in the article's Creative Commons licence, unless indicated otherwise in a credit line to the material. If material is not included in the article's Creative Commons licence and your intended use is not permitted by statutory regulation or exceeds the permitted use, you will need to obtain permission directly from the copyright holder. To view a copy of this licence, visit http://creativecommons.org/licenses/by/4.0/.

\section{References}

1. Wilkoff BL, Love CJ, Byrd CL, Bongiorni MG, Carrillo RG, Crossley GH 3rd, et al. Transvenous lead extraction: Heart Rhythm Society expert consensus on facilities, training, indications, and patient management: this document was endorsed by the American Heart Association (AHA). Heart Rhythm. 2009;6(7):1085-104.

2. Di Monaco A, Pelargonio G, Narducci ML, Manzoli L, Boccia S, Flacco ME, et al. Safety of transvenous lead extraction according to centre volume: a systematic review and meta-analysis. Europace. 2014;16(10):1496-507.

3. Hauser RG, Katsiyiannis WT, Gornick CC, Almquist AK, Kallinen LM. Deaths and cardiovascular injuries due to deviceassisted implantable cardioverter-defibrillator and pacemaker lead extraction. Europace. 2010;12(3):395-401.

4. Diemberger I, Mazzotti A, Giulia MB, Cristian M, Matteo M, Letizia ZM, et al. From lead management to implanted patient management: systematic review and meta-analysis of the last 15 years of experience in lead extraction. Expert Rev Med Devices. 2013;10(4):551-73.

5. Maytin M, Epstein LM, Henrikson CA. Lead extraction is preferred for lead revisions and system upgrades: when less is more. Circ Arrhythm Electrophysiol. 2010;3(4):413-24 (discussion 24).

6. Mazzone P, Tsiachris D, Marzi A, Ciconte G, Paglino G, Sora $\mathrm{N}$, et al. Advanced techniques for chronic lead extraction: heading from the laser towards the evolution system. Europace. 2013;15(12):1771-6.

7. Mazzone P, Migliore F, Bertaglia E, Facchin D, Daleffe E, Calzolari $\mathrm{V}$, et al. Safety and efficacy of the new bidirectional rotational Evolution(R) mechanical lead extraction sheath: results from a multicentre Italian registry. EP Europace. 2018;20(5):829834. https://doi.org/10.1093/europace/eux020

8. Wazni O, Epstein LM, Carrillo RG, Love C, Adler SW, Riggio DW, et al. Lead extraction in the contemporary setting: the LExICon study: an observational retrospective study of consecutive laser lead extractions. J Am Coll Cardiol. 2010;55(6):579-86.

9. Manzoli L, De Vito C, Salanti G, D’Addario M, Villari P, Ioannidis JP. Meta-analysis of the immunogenicity and tolerability of pandemic influenza A 2009 (H1N1) vaccines. PLoS One. 2011;6(9):e24384.

10 Stroup DF, Berlin JA, Morton SC, Olkin I, Williamson GD, Rennie D, et al. Meta-analysis of observational studies in epidemiology: a proposal for reporting. Meta-analysis Of Observational Studies in Epidemiology (MOOSE) group. JAMA. 2000;283(15):2008-12.

11. Bordachar P, Defaye P, Peyrouse E, Boveda S, Mokrani B, Marquie C, et al. Extraction of old pacemaker or cardioverterdefibrillator leads by laser sheath versus femoral approach. Circ Arrhythm Electrophysiol. 2010;3(4):319-23.

12. Wilkoff BL, Byrd CL, Love CJ, Hayes DL, Sellers TD, Schaerf $\mathrm{R}$, et al. Pacemaker lead extraction with the laser sheath: results of the pacing lead extraction with the excimer sheath (PLEXES) trial. J Am Coll Cardiol. 1999;33(6):1671-6.
13. Delnoy PP, Witte OA, Adiyaman A, Ghani A, Smit JJ, RamdatMisier AR, et al. Lead extractions: the Zwolle experience with the Evolution mechanical sheath. Europace. 2016;18(5):762-6.

14. Roux JF, Page P, Dubuc M, Thibault B, Guerra PG, Macle L, et al. Laser lead extraction: predictors of success and complications. Pacing Clin Electrophysiol. 2007;30(2):214-20.

15. Domenichini G, Gonna H, Sharma R, Conti S, Fiorista L, Jones S, et al. Non-laser percutaneous extraction of pacemaker and defibrillation leads: a decade of progress. Europace. 2017;19(9):1521-6.

16. Aytemir K, Yorgun H, Canpolat U, Sahiner ML, Kaya EB, Evranos B, et al. Initial experience with the TightRail Rotating Mechanical Dilator Sheath for transvenous lead extraction. Europace. 2016;18(7):1043-8.

17. Kocabas U, Duygu H, Eren NK, Akyildiz ZI, Ozyildirim S, Tuluce SY, et al. Transvenous extraction of pacemaker and implantable cardioverter defibrillator leads using Evolution(R) mechanical dilator sheath: a single center confirmatory experience. Springerplus. 2016;5:356.

18. Starck CT, Steffel J, Caliskan E, Holubec T, Schoenrath F, Maisano $\mathrm{F}$, et al. Clinical performance of a new bidirectional rotational mechanical lead extraction sheath. Europace. 2016;18(2):253-6.

19. Kong J, Tian Y, Guo F, Ze F, Duan J, Wang L, et al. Snare sheath versus evolution sheath in transvenous lead extraction. Int J Clin Exp Med. 2015;8(11):21975-80.

20. Oto A, Aytemir K, Canpolat U, Yorgun H, Sahiner L, Kaya EB, et al. Evolution in transvenous extraction of pacemaker and implantable cardioverter defibrillator leads using a mechanical dilator sheath. Pacing Clin Electrophysiol. 2012;35(7):834-40.

21. Oto A, Aytemir K, Yorgun H, Canpolat U, Kaya EB, Kabakci $\mathrm{G}$, et al. Percutaneous extraction of cardiac pacemaker and implantable cardioverter defibrillator leads with evolution mechanical dilator sheath: a single-centre experience. Europace. 2011;13(4):543-7.

22. Hussein AA, Wilkoff BL, Martin DO, Karim S, Kanj M, Callahan $\mathrm{T}$, et al. Initial experience with the Evolution mechanical dilator sheath for lead extraction: safety and efficacy. Heart Rhythm. 2010;7(7):870-3.

23. Kutarski A, Malecka B, Rucinski P, Zabek A. Percutaneous extraction of endocardial leads-a single centre experience in 120 patients. Kardiol Pol. 2009;67(2):149-56 (discussion 57-8).

24. Pecha S, Yildirim Y, Gosau N, Aydin MA, Willems S, Treede H, et al. Laser lead extraction allows for safe and effective removal of single- and dual-coil implantable cardioverter defibrillator leads: a single-centre experience over 12 years. Interact Cardiovasc Thorac Surg. 2017;24(1):77-81.

25. Pecha S, Linder M, Gosau N, Castro L, Vogler J, Willems S, et al. Lead extraction with high frequency laser sheaths: a single-centre experience. Eur J Cardiothorac Surg. 2017;51(5):902-5.

26. Williams KJ, O'Keefe S, Legare JF. Creation of the sole regional laser lead extraction program serving Atlantic Canada: initial experience. Can J Surg. 2016;59(3):180-7.

27. Fu HX, Huang XM, Zhong LI, Osborn MJ, Asirvatham SJ, Espinosa RE, et al. Outcomes and complications of lead removal: can we establish a risk stratification schema for a collaborative and effective approach? Pacing Clin Electrophysiol. 2015;38(12):1439-47.

28. Hakmi S, Pecha S, Sill B, Reiter B, Willems S, Aydin MA, et al. Initial experience of pacemaker and implantable cardioverter defibrillator lead extraction with the new GlideLight $80 \mathrm{~Hz}$ laser sheaths. Interact Cardiovasc Thorac Surg. 2014;18(1):56-60.

29. Tanawuttiwat T, Gallego D, Carrillo RG. Lead extraction experience with high frequency excimer laser. Pacing Clin Electrophysiol. 2014;37(9):1120-8.

30. Sohal M, Williams S, Akhtar M, Shah A, Chen Z, Wright M, et al. Laser lead extraction to facilitate cardiac implantable electronic 
device upgrade and revision in the presence of central venous obstruction. Europace. 2014;16(1):81-7.

31. Wang W, Wang X, Modry D, Wang S. Cardiopulmonary bypass standby avoids fatality due to vascular laceration in laser-assisted lead extraction. J Card Surg. 2014;29(2):274-8.

32. Okamura H. Lead extraction using a laser system: techniques, efficacy, and limitations. J Arrhythm. 2016;32(4):279-82.

33 Starck CT, Rodriguez H, Hurlimann D, Grunenfelder J, Steffel J, Salzberg SP, et al. Transvenous lead extractions: comparison of laser vs. mechanical approach. Europace. 2013;15(11):1636-41.

34. Patel D, Adelstein E, Nemec J, Mendenhall GS, Bazaz R, Jain S, et al. Extraction of defibrillator leads recalled for cable externalization and failure. J Interv Card Electrophysiol. 2013;36(3):273-8.

35. Maytin M, Epstein LM, John RM. Lead implant duration does not always predict ease of extraction: extraction sheath may be required at $<1$ year. Pacing Clin Electrophysiol. 2011;34(12):1615-20.

36. Maytin M, Henrikson CA, Schaerf RH, Epstein LM, John RM. Multicenter experience with transvenous lead extraction in arrhythmogenic right ventricular cardiomyopathy (ARVC). Pacing Clin Electrophysiol. 2013;36(10):1280-3.

37. Rodriguez Y, Garisto JD, Carrillo RG. Laser lead extraction in the octogenarian patient. Circ Arrhythm Electrophysiol. 2011;4(5):719-23.

38. Kratz JM, Toole JM. Pacemaker and internal cardioverter defibrillator lead extraction: a safe and effective surgical approach. Ann Thorac Surg. 2010;90(5):1411-7.

39. Gaca JG, Lima B, Milano CA, Lin SS, Davis RD, Lowe JE, et al. Laser-assisted extraction of pacemaker and defibrillator leads: the role of the cardiac surgeon. Ann Thorac Surg. 2009;87(5):144650 (discussion 50-1)

40. Scott PA, Chow W, Ellis E, Morgan JM, Roberts PR. Extraction of pacemaker and implantable cardioverter defibrillator leads: a single-centre study of electrosurgical and laser extraction. Europace. 2009;11(11):1501-4.

41. Kennergren C, Bucknall CA, Butter C, Charles R, Fuhrer J, Grosfeld M, et al. Laser-assisted lead extraction: the European experience. Europace. 2007;9(8):651-6.

42. Moak JP, Freedenberg V, Ramwell C, Skeete A. Effectiveness of excimer laser-assisted pacing and ICD lead extraction in children and young adults. Pacing Clin Electrophysiol. 2006;29(5):461-6.

43. Bracke FA, Meijer A, van Gelder LM. Lead extraction for device related infections: a single-centre experience. Europace. 2004;6(3):243-7.

44. Cooper JM, Stephenson EA, Berul CI, Walsh EP, Epstein LM. Implantable cardioverter defibrillator lead complications and laser extraction in children and young adults with congenital heart disease: implications for implantation and management. J Cardiovasc Electrophysiol. 2003;14(4):344-9.

45. Byrd CL, Wilkoff BL, Love CJ, Sellers TD, Reiser C. Clinical study of the laser sheath for lead extraction: the total experience in the United States. Pacing Clin Electrophysiol. 2002;25(5):804-8.

46. Costa R, Martinelli Filho M, Crevelari ES, Stolf NA, Oliveira SA. Laser assisted extraction of pacemaker and implantable defibrillator leads. Arq Bras Cardiol. 2001;77(3):235-42.

47. Gilligan DM, Dan D. Excimer laser for pacemaker and defibrillator lead extraction: techniques and clinical results. Lasers Med Sci. 2001;16(2):113-21.
48. Epstein LM, Byrd CL, Wilkoff BL, Love CJ, Sellers TD, Hayes $\mathrm{DL}$, et al. Initial experience with larger laser sheaths for the removal of transvenous pacemaker and implantable defibrillator leads. Circulation. 1999;100(5):516-25.

49. Kennergren C. First European experience using excimer laser for the extraction of permanent pacemaker leads. Pacing Clin Electrophysiol. 1998;21(1 Pt 2):268-70.

50. Krishnan SC, Epstein LM. Initial experience with a laser sheath to extract chronic transvenous implantable cardioverter-defibrillator leads. Am J Cardiol. 1998;82(10):1293-5 (A10).

51. Sharma S, Raman AS, Hematpour K, Venkataraman R, Hariharan R. Safety and efficacy of the cook medical evolution ${ }^{\circledR}$ mechanical lead extraction system: a single center experience. Heart Rhythm. 2015;12(5):S253.

52. Ghosh N, Yee R, Klein GJ, Quantz M, Novick RJ, Skanes AC, et al. Laser lead extraction: is there a learning curve? Pacing Clin Electrophysiol. 2005;28(3):180-4.

53. Aksu T, Guray U, Sen T, Durukan M, Guray Y, Demirkan B, et al. Use of the mechanical dilator sheath for removal of endocardial leads: a single center experience. Pacing Clin Electrophysiol. 2012;35(5):514-8.

54. Reynolds TM, National Institute for H, Clinical E, Clinical Scince Reviews Committee of the Association for Clinical B. National Institute for Health and Clinical Excellence guidelines on preoperative tests: the use of routine preoperative tests for elective surgery. Ann Clin Biochem. 2006;43(Pt 1):13-6.

55. Deharo JC, Bongiorni MG, Rozkovec A, Bracke F, Defaye P, Fernandez-Lozano I, et al. Pathways for training and accreditation for transvenous lead extraction: a European Heart Rhythm Association position paper. Europace. 2012;14(1):124-34.

56. Diaz CL, Guo X, Whitman IR, Marcus GM, Pellegrini CN, Beygui RE, et al. Reported mortality with rotating sheaths vs laser sheaths for transvenous lead extraction. Europace. 2019;21(11):1703-9.

57. Zucchelli G, Di Cori A, Segreti L, Laroche C, Blomstrom-Lundqvist C, Kutarski A, et al. Major cardiac and vascular complications after transvenous lead extraction: acute outcome and predictive factors from the ESC-EHRA ELECTRa (European Lead Extraction ConTRolled) registry. EP Europace. 2019;21(5):771780. https://doi.org/10.1093/europace/euy300.

58 Wilkoff BL, Kennergren C, Love CJ, Kutalek SP, Epstein LM, Carrillo R. Bridge to surgery: Best practice protocol derived from early clinical experience with the Bridge Occlusion. Balloon Federated Agreement from the Eleventh Annual Lead Management Symposium. Heart Rhythm. 2017;14(10):1574-8.

Publisher's note Springer Nature remains neutral with regard to jurisdictional claims in published maps and institutional affiliations. 


\section{Authors and Affiliations}

\section{Sun Yong Lee ${ }^{1,2}$ (1) Isabel E. Allen ${ }^{3} \cdot$ Celso Diaz ${ }^{4,5} \cdot$ Xiaofan Guo $^{3,6} \cdot$ Cara Pellegrini $^{1,7} \cdot$ Ramin Beygui $^{8} \cdot$ Ricardo Cardona-Guarache ${ }^{9} \cdot$ Gregory M. Marcus $^{1} \cdot$ Byron K. Lee $^{1}$}

Isabel E. Allen

isabel.allen@ucsf.edu

Celso Diaz

celso.diaz@northwestern.edu

Xiaofan Guo

guoxiaofan1986@hotmail.com

Cara Pellegrini

Cara.Pellegrini@va.gov

Ramin Beygui

Ramin.Beygui@ucsf.edu

Ricardo Cardona-Guarache

Ricardo.CardonaGuarache@ucsf.edu

Gregory M. Marcus

Greg.Marcus@ucsf.edu

Byron K. Lee

Byron.Lee@ucsf.edu

1 Division of Cardiology, University of California, San Francisco, San Francisco, CA 94143, USA

2 Department of Internal Medicine, San Joaquin General Hospital, 500 W Hospital Rd, French Camp, CA 95231, USA
3 Department of Epidemiology and Biostatistics, University of California, San Francisco, San Francisco, CA 94143, USA

4 School of Medicine, University of California, San Francisco, San Francisco, CA 94143, USA

5 Department of Medicine, Northwestern University, Chicago, IL 60611, USA

6 Department of Cardiology, The First Hospital of China Medical University, Shenyang, Liaoning, China

7 Division of Cardiology, San Francisco VAMC, San Francisco, CA 94121, USA

8 Division of Adult Cardiothoracic Surgery, San Francisco, CA 94143, USA

9 Department of Heart and Vascular (Cardiology), Clinical Cardiac Electrophysiology, The Everett Clinic, Everett, WA 98201, USA 